\title{
LC-UV Determination of Baicalin in Rabbit Plasma and Tissues for Application in Pharmacokinetics and Tissue Distribution Studies of Baicalin after Intravenous Administration of Liposomal and Injectable Formulations
}

\author{
Yumeng Wei ${ }^{1}$, Chao $\mathrm{Pi}^{1}$, Gang Yang ${ }^{2}$, Xiaoming Xiong ${ }^{3}$, Yongshu Lan ${ }^{4}$, Hongru Yang ${ }^{5}$, \\ Yang Zhou ${ }^{1}$, Yun Ye ${ }^{1,6}$, Yonggen Zou ${ }^{7}$, Wenwu Zheng ${ }^{8}$ and Ling Zhao ${ }^{1, *}$ \\ 1 Department of Pharmaceutical Sciences, School of Pharmacy, Southwest Medical University, No. 3-319, \\ Zhongshan Road, Jiangyang District, Luzhou 646000, China; weiyumeng-268@163.com (Y.W.); \\ pichao2016@sina.com (C.P.); zhouyg2014@sina.com (Y.Z.); zl2006998@126.com (Y.Y.) \\ 2 Department of Chemistry, the Institute of Basic Medical Sciences, Southwest Medical University, No. 3-319, \\ Zhongshan Road, Jiangyang District, Luzhou 646000, China; gangy405@163.com \\ 3 Department of Pathology, the Affiliated Hospital of Southwest Medical University, No. 25, Taiping Street, \\ Luzhou 646000, China; zl2006998@sina.com \\ 4 Department of Radiology, the Affiliated Hospital of Southwest Medical University, No. 25, Taiping Street, \\ Luzhou 646000, China; LYBLUE2008@aliyun.com \\ 5 Department of Oncology, the Affiliated Hospital of Southwest Medical University, No. 25, Taiping Street, \\ Luzhou 646000, China; yanghr2015@sina.com \\ 6 Department of Pharmacy, the Affiliated Hospital of Southwest Medical University, No. 25, Taiping Street, \\ Luzhou 646000, China \\ 7 Department of Orthopedics, the Affiliated Hospital of Traditional Chinese Medicine of Southwest Medical \\ University, No. 16, Chunhui Road, Longma Tan District, Luzhou 646000, China; zouyg2015@sina.com \\ 8 Department of Cardiovascular Medicine, The Affiliated Hospital of Southwest Medical University, No. 25, \\ Taiping Street, Luzhou 646000, China; weilivipcqmc@163.com \\ * Correspondence: zhaoling-998@163.com; Tel./Fax: +86-830-3162-291
}

Academic Editor: Derek J. McPhee

Received: 16 February 2016; Accepted: 24 March 2016; Published: 19 April 2016

\begin{abstract}
A simple and sensitive LC-UV method to investigate the pharmacokinetics and biodistribution pattern of baicalin in rabbits was established and validated. Baicalin and the internal standard, rutin, were extracted from biosamples using acetonitrile as protein precipitation after pretreated with ammonium acetate buffer $(\mathrm{pH} 3.5 ; 1 \mathrm{M})$ to obtain a pure chromatographic peak and high extraction recovery. Chromatographic separation was achieved on a reverse-phase C18 column with a gradient elution at flow rate of $1.0 \mathrm{~mL} / \mathrm{min}$. UV absorption was set at $278 \mathrm{~nm}$. Chromatographic response was linear over the ranges of $0.05-10.00 \mu \mathrm{g} / \mathrm{mL}$ in plasma and $0.05-300.00 \mu \mathrm{g} / \mathrm{g}$ in tissues with the limits of quantification of $50.0 \mathrm{ng} / \mathrm{mL}$ in plasma and tissues, and the limit of detection of baicalin in bio-samples of $15 \mathrm{ng} / \mathrm{mL}$. The RSD of intra-and inter-day for the biosamples were from $4.19 \%$ to $10.84 \%$ and from $4.37 \%$ to $10.93 \%$, respectively. The accuracy of plasma and tissue samples ranged from $81.6 \%$ to $95.2 \%$ and $80.8 \%$ to $98.4 \%$, respectively. The extraction recoveries ranged from $81.5 \%$ to $88.3 \%$ for plasma, from $73.1 \%$ to $93.2 \%$ for tissues, respectively. Baicalin was stable in rabbit biosamples. The validated method was successfully applied to the study of the pharmacokinetics and tissue distribution of baicalin after intravenous administration of liposomal and injectable formulations to rabbits. Compared to baicalin injection, the pharmacokinetics and biodistribution behavior of baicalin was altered significantly in rabbits treated with its liposomes and drug concentration in the lungs was greatly increased.
\end{abstract}


Keywords: pharmacokinetics; tissue distribution; LC-UV; lung targeting; baicalin

\section{Introduction}

Baicalin (7-glucuronic acid-5,6-dihydroxy-flavone, Figure 1), as one of the main bioactive flavone compounds, was isolated from the Radix Scutellariae that is a well-known traditional Chinese medicine used to treat diarrhea, fever, inflammatory and hepatic disease, and so on, in many countries [1]. Recently, a great deal of studies regarding baicalin have presented its excellent pharmacological anti-inflammation [2], anti-oxidation [3], anti-bacterial and anti-tumor activities [4,5]. At present, baicalin was widely used in the clinic either as a single compound such as its tablets and capsules or as a main active component in more than 40 kinds of preparations recorded in the Chinese Pharmacopeia (2015). However, the further development of baicalin was limited due to its low hydrophilicity, which has serious effects on the clinical use [6]. Many attempts have been made to develop new drug delivery systems for baicalin, such as inclusion complexes [7], nanoemulsions [8], solid lipid nanoparticles [9], phospholipid complexes and polyvinylpyrrolidone co-precipitate in order to improve the oral bioavailability [10-12]. Although these drug delivery systems were all used to increase its oral bioavailability to some extent, there are still some difficulties in meeting the requirements for clinical application and industrial production.

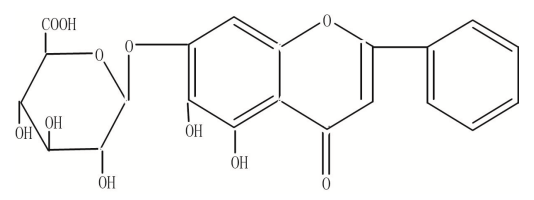

Figure 1. Chemical structure of baicalin.

A recent study of baicalin indicated that it could inhibit proliferation of human lung carcinoma A549 and mouse Lewis lung cancer (LLC) in a dose- and time-dependent manner. It also could suppress tumor growth and prolong survival in C57BL/ 6 mice bearing LLC tumor and nude mice bearing A549 carcinoma [13]. Moreover, baicalin also could relieve lung injuries related to pancreatitis to some extent [14]. This made it necessary for us to develop a lung-targeting drug delivery system for baicalin. Interestingly, in the preliminary experiments, baicalin loaded liposomes prepared by an effervescent technique displayed lung targeting effects for the first time. This made it necessary to establish a simple and sensitive analytical method for the determination of baicalin in plasma and tissues to characterize its pharmacokinetics and tissue distribution patterns. The existing in vivo analytical methods for baicalin in plasma, serum, urine had been well developed mainly using the techniques of LC-UV [15], LC-MS [16], LC-DAD [17], UPLC-MS and enzyme-linked immunosorbent assay (icELISA) $[18,19]$. However, to date, to the best of our knowledge, the pharmacokinetics and tissue distribution of baicalin in rabbits via intravenous administration of its liposomal formulations have not yet been reported in the literature.

The objective of this study was thus to establish and validate for the first time a simple and sensitive LC-UV method to determine baicalin in rabbit plasma and tissue samples. The analytical method was applied successfully to investigate pharmacokinetics and tissue distribution characteristics of baicalin after a single intravenous administration of liposomal and injectable formulation to rabbits. This study was conducted to help design rational new dosage form of baicalin and evaluate its clinical effect.

\section{Results and Discussion}

\subsection{Characteristics of Baicalin Loaded Liposomes}

The freeze dried powders or granules of baicalin loaded liposomes were redissolved with ultrapure water to obtain a transparent and yellow solution. Particle size and PDI of baicalin-loaded 
liposomes measured by a NanoBrook 90 Plus Zeta instrument (Brookhaven Instruments, Holtsville, NY, USA) were $131.7 \pm 11.7 \mathrm{~nm}$ and $0.19 \pm 0.02$, respectively. The entrapment efficiency of baicalinloaded liposomes was $82.8 \% \pm 1.24 \%$, which was higher than the values $(34.62 \%-60.11 \%)$ reported in the literature $[20,21]$. It was well known that there are significant differences in entrapment efficiency of liposomes prepared using different formulations and preparation technologies.

\subsection{Optimization of Chromatographic Condition}

According to several reports, a LC-UV method for the determination of baicalin in plasma was established using a reverse-phase column and various ratios of organic phases including acetonitrile or methanol and an aqueous phase including $0.2 \%(v / v)$ phosphoric acid or $0.1 \%(v / v)$ aqueous formic acid [22,23]. In preliminary experiments, these mobile phases were tried but acceptable peak symmetry and theoretical plates were not obtained. The acid concentration in the aqueous phase and the volumetric ratio of acetonitrile and methanol were found to significantly affect the peak symmetry and theoretical plates. In order to obtain symmetrical peaks and the best resolution of baicalin from endogenous compounds, various acid concentrations in the aqueous phase and ratios of acetonitrile and methanol were tested and optimized. As a result, a final mobile phase consisting of 1:1 (v/v) mixture of methanol and acetonitrile $(\mathrm{A})$ and $0.4 \%(v / v)$ aqueous phosphoric acid $(\mathrm{B})$ using a gradient elution of $85 \%$ B at $0-1 \mathrm{~min}, 85 \%-30 \%$ B at $1-14 \mathrm{~min}, 30 \%-85 \%$ B at $14-15 \mathrm{~min}$ was used to obtain satisfactory results in this study.

\subsection{Assay Validation}

\subsubsection{Selectivity}

Typical chromatograms obtained with blank plasma or blank lung tissue homogenate as representative samples, blank plasma or blank lung homogenate spiked with baicalin or IS, and a plasma or lung tissue sample collected at $0.25 \mathrm{~h}$ spiked with IS after intravenous administration of baicalin loaded liposomes were shown in Figures 2 and 3 respectively. To compare the chromatograms of samples from the other organs including heart, liver, spleen, kidney, brain and stomach, typical chromatograms obtained with blank tissue homogenates and tissue samples are shown in Figures 4-9 respectively. It can be seen that a well-resolved baicalin peak free of interferences from endogenous compounds in rabbit plasma and tissues, was obtained, with a retention time of $12.8 \mathrm{~min}$, which was shorter than previous results which ranged from 13.4 to $14.3 \mathrm{~min}[12,23,24]$. In addition, the retention time of the IS was $10.4 \mathrm{~min}$, which was obviously well separated from the peak of baicalin. Therefore, The LC-UV analytical method had good selectivity.
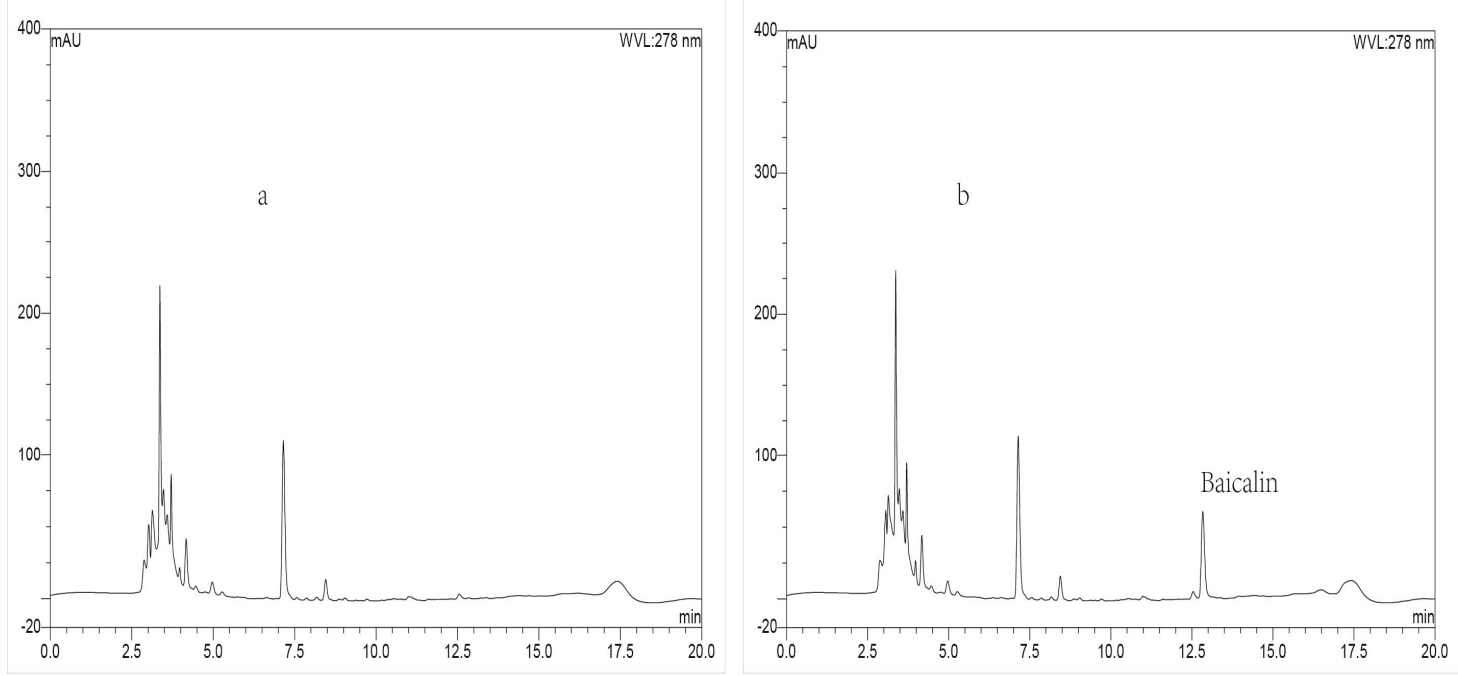

Figure 2. Cont. 

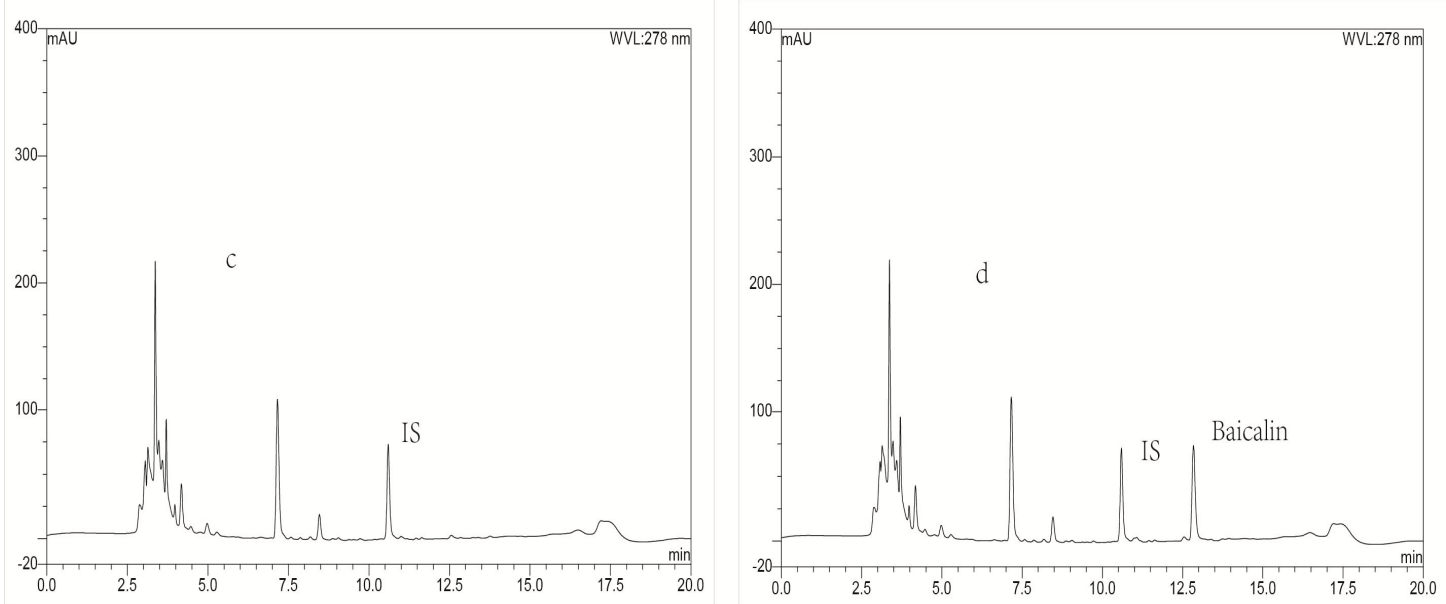

Figure 2. Representative LC-UV chromatograms obtained for blank plasma (a); blank plasma spiked with baicalin (b); blank plasma spiked with IS (c) and plasma biosample collected from a rabbit at $0.25 \mathrm{~h}$ after intravenous administration of baicalin-loaded liposomes at a dose of $10 \mathrm{mg} / \mathrm{kg}+\mathrm{IS}$ (d).
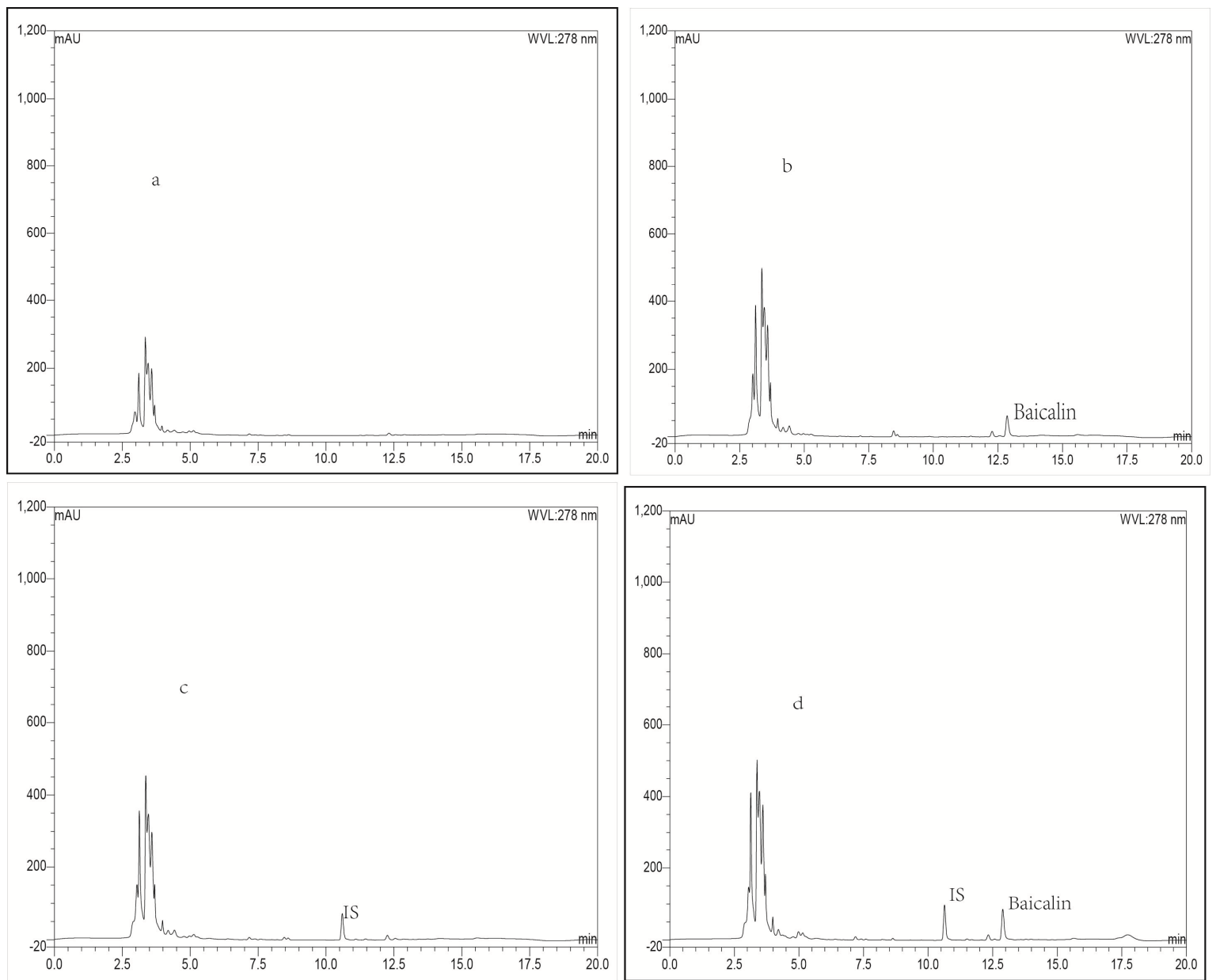

Figure 3. Representative LC-UV chromatograms obtained for blank lung tissue (a); blank lung tissue spiked with baicalin (b); blank lung tissue spiked with IS (c) and lung biosample collected from a rabbit at $0.25 \mathrm{~h}$ after intravenous administration of baicalin-loaded liposomes at a dose of $10 \mathrm{mg} / \mathrm{kg}+\mathrm{IS}(\mathbf{d})$. 

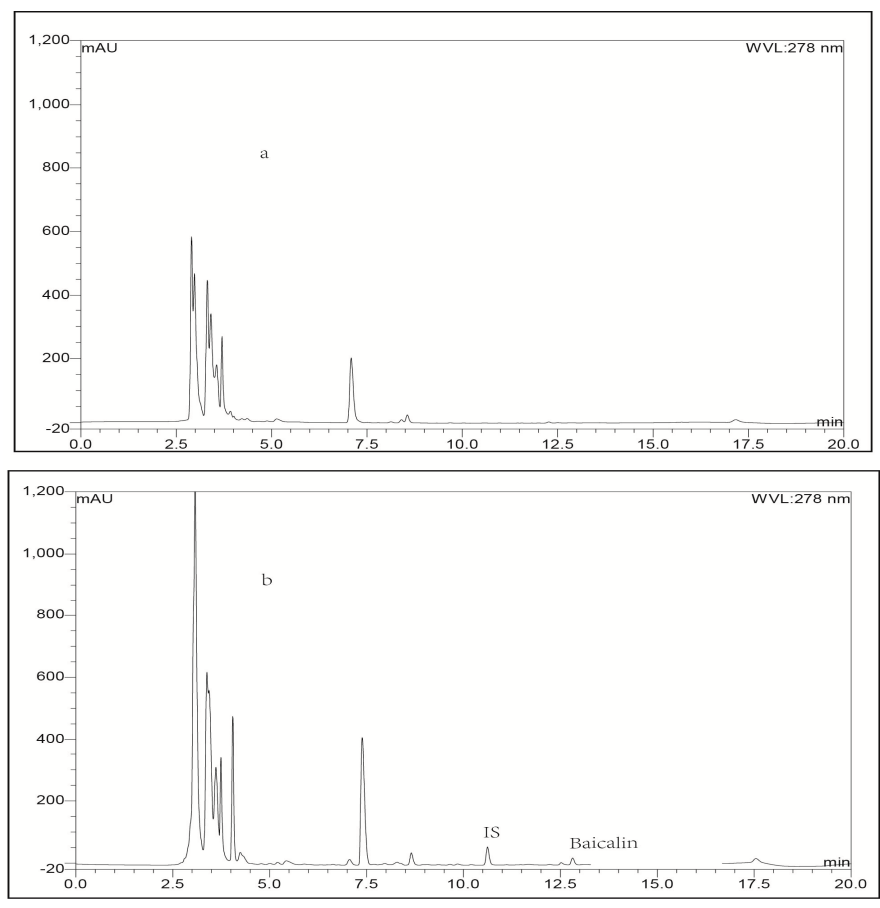

Figure 4. Representative LC-UV chromatograms obtained for blank heart tissue (a) and heart bio-sample collected from a rabbit at $0.25 \mathrm{~h}$ after intravenous administration of baicalin-loaded liposomes at a dose of $10 \mathrm{mg} / \mathrm{kg}+\mathrm{IS}(\mathbf{b})$.
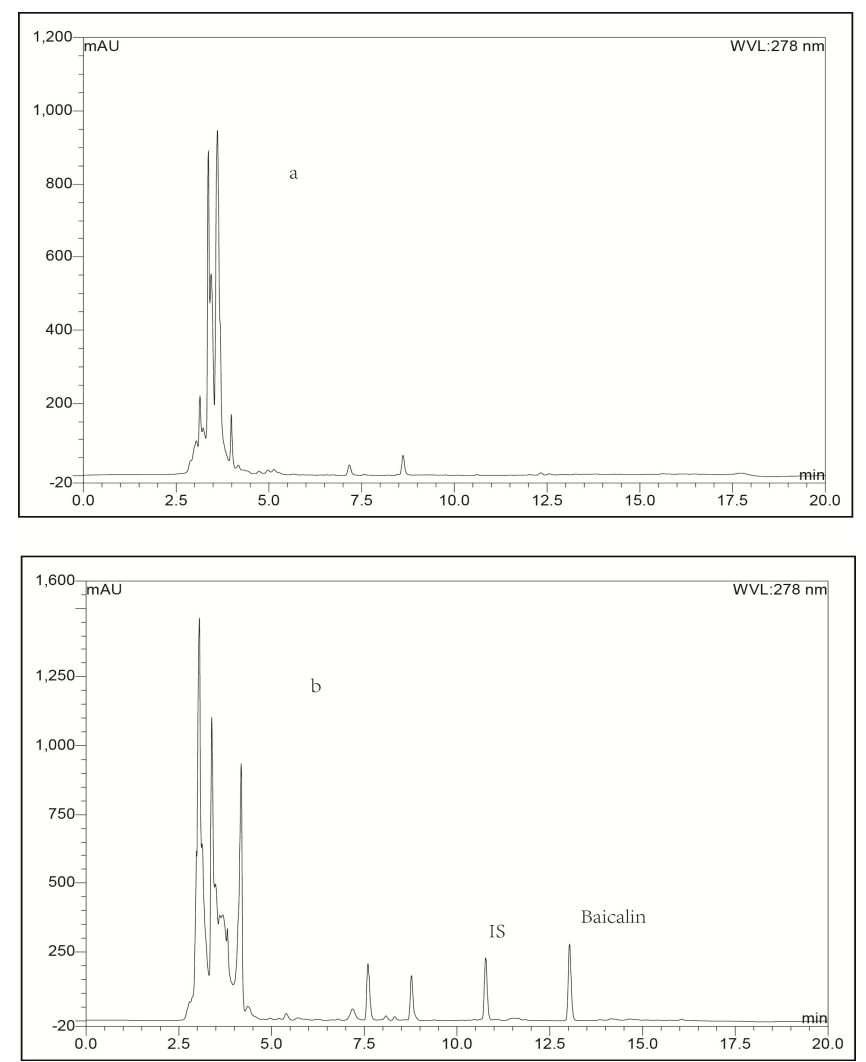

Figure 5. Representative LC-UV chromatograms obtained for blank liver tissue (a) and liver bio-sample collected from a rabbit at $0.25 \mathrm{~h}$ after intravenous administration of baicalin-loaded liposomes at a dose of $10 \mathrm{mg} / \mathrm{kg}+\mathrm{IS}(\mathbf{b})$. 

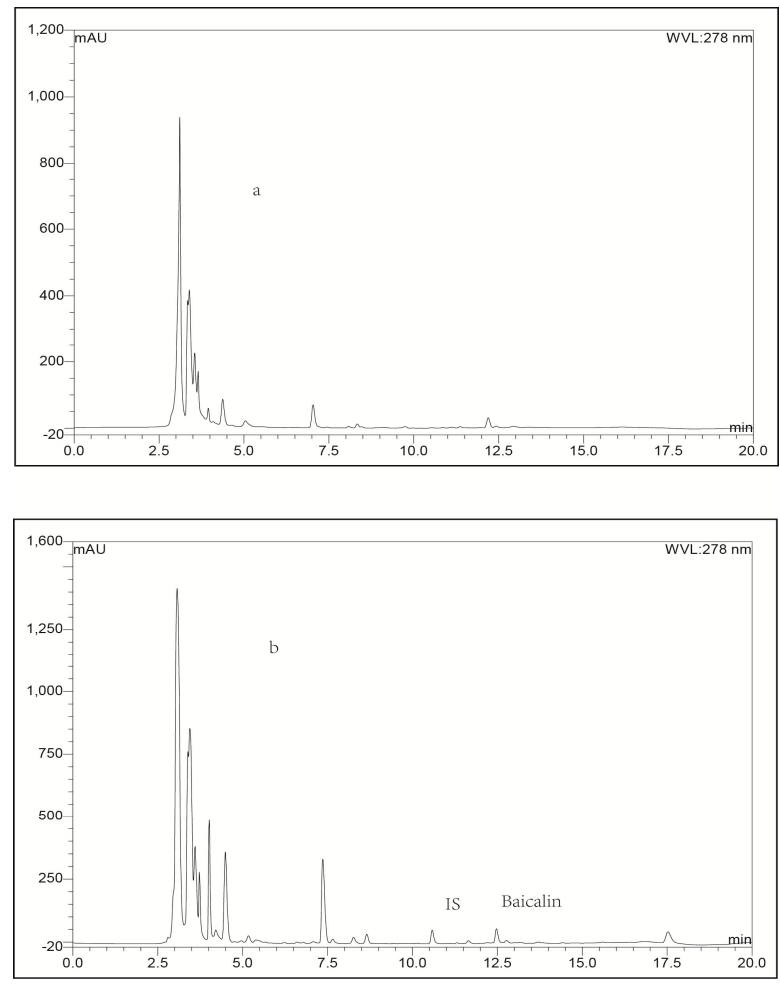

Figure 6. Representative LC-UV chromatograms obtained for blank spleen tissue (a) and spleen bio-sample collected from a rabbit at $0.25 \mathrm{~h}$ after intravenous administration of baicalin-loaded liposomes at a dose of $10 \mathrm{mg} / \mathrm{kg}+\mathrm{IS}(\mathbf{b})$.
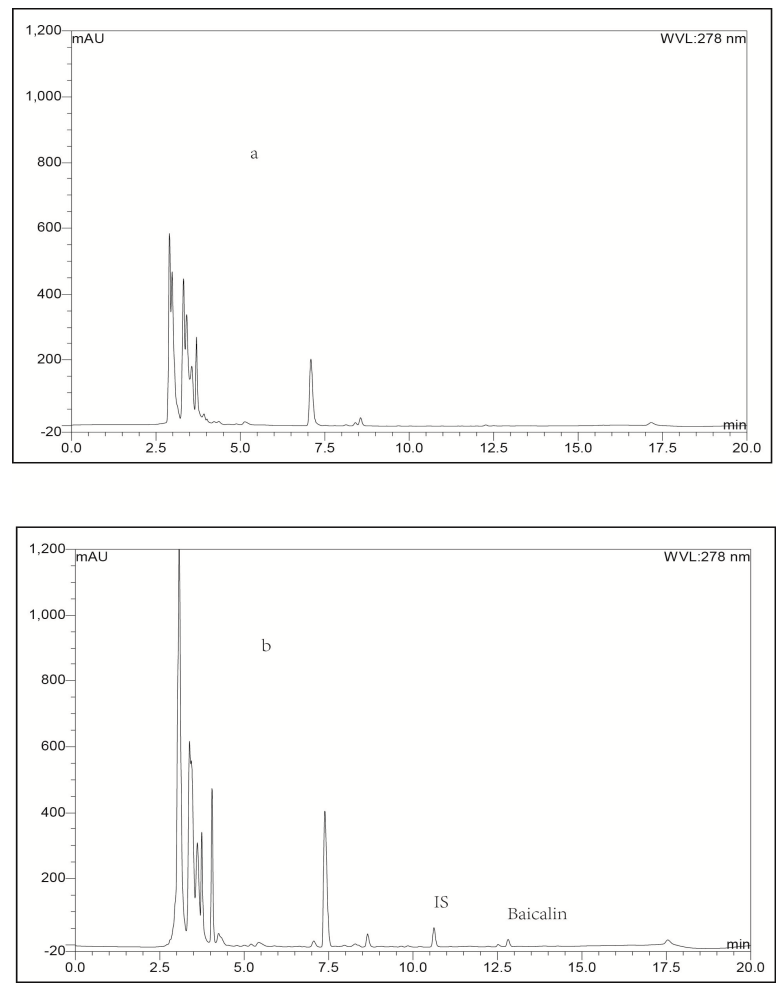

Figure 7. Representative LC-UV chromatograms obtained for blank kidney tissue (a) and kidney bio-sample collected from a rabbit at $0.25 \mathrm{~h}$ after intravenous administration of baicalin-loaded liposomes at a dose of $10 \mathrm{mg} / \mathrm{kg}+\mathrm{IS}(\mathbf{b})$. 

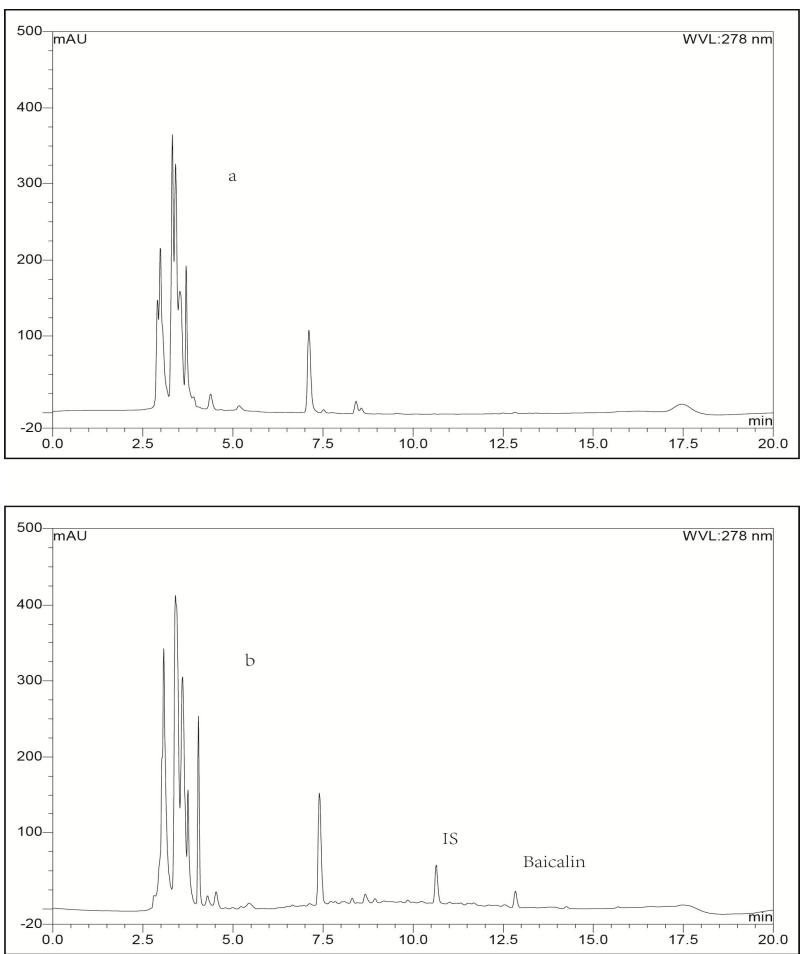

Figure 8. Representative LC-UV chromatograms obtained for blank stomach tissue (a) and stomach bio-sample collected from a rabbit at $0.25 \mathrm{~h}$ after intravenous administration of baicalin-loaded liposomes at a dose of $10 \mathrm{mg} / \mathrm{kg}+$ IS (b).
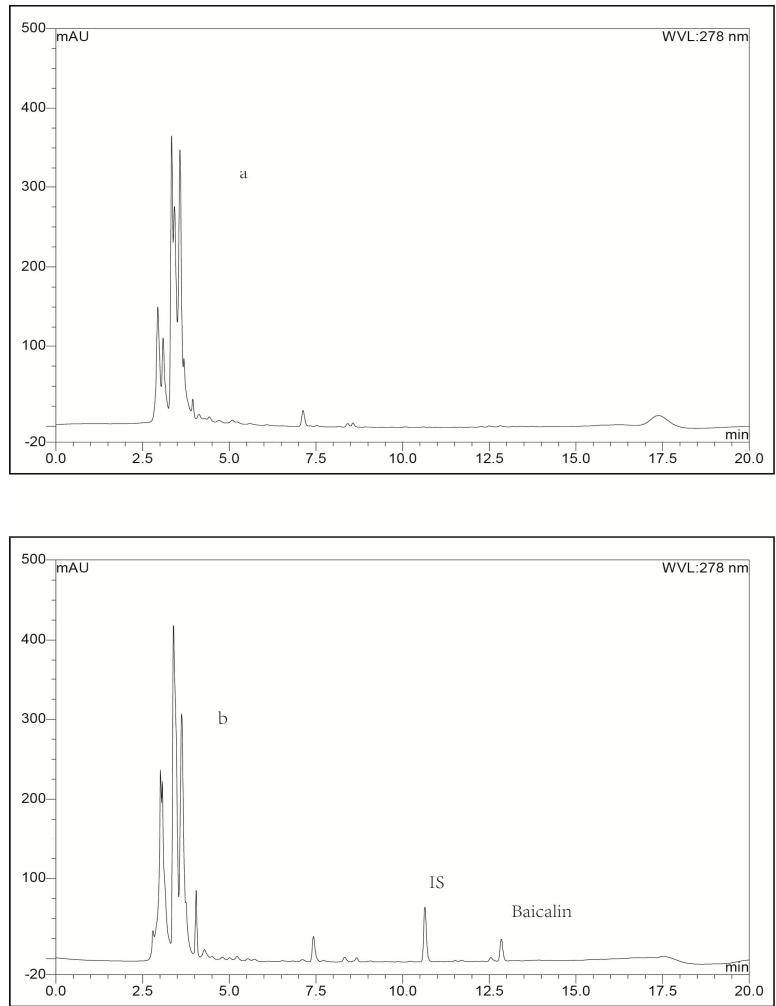

Figure 9. Representative LC-UV chromatograms obtained for blank brain tissue (a) and brain bio-sample collected from a rabbit at $0.25 \mathrm{~h}$ after intravenous administration of baicalin-loaded liposomes at a dose of $10 \mathrm{mg} / \mathrm{kg}+\mathrm{IS}(\mathbf{b})$. 


\subsubsection{Linearity Range, Limit of Quantification and Limit of Detection}

Calibration curves of the peak area ratio of baicalin and IS (R) versus drug concentration (C) in plasma and tissues were plotted and the linear range and correlation coefficient (r) are presented in Table 1. The results were found to be linear within the ranges of $0.05-10 \mu \mathrm{g} / \mathrm{mL}$ for plasma, 0.05-10 $\mu \mathrm{g} / \mathrm{g}$ for heart, brain and spleen, $0.2-10 \mu \mathrm{g} / \mathrm{g}$ for kidney, $0.05-5 \mu \mathrm{g} / \mathrm{g}$ for stomach, $0.2-5 \mu \mathrm{g} / \mathrm{g}$ for liver, $0.75-300 \mu \mathrm{g} / \mathrm{g}$ for lung, ( $\mathrm{r}>0.999$ ). The assay method offered limits of quantification (LOQ) of $50.0 \mathrm{ng} / \mathrm{mL}$ in plasma and $50.0 \mathrm{ng} / \mathrm{g}$ in tissue homogenate samples, and the limit of detection (LOD) of baicalin in plasma and tissue samples were $15 \mathrm{ng} / \mathrm{mL}$ and $15 \mathrm{ng} / \mathrm{g}$, respectively, which were lower than the results reported in [23]. This suggested that this LC-UV analytical method is sensitive enough for study of the pharmacokinetic and tissue distribution behavior of baicalin in rabbits.

Table 1. Linear ranges, standard curves and correlation coefficients of baicalin in different rabbit biosamples ${ }^{\text {a }}$.

\begin{tabular}{|c|c|c|c|}
\hline Biosample & Standard Curves & Linear Ranges $(\mu \mathrm{g} / \mathrm{g} \text { or } \mu \mathrm{g} / \mathrm{mL})^{b}$ & Correlation Coefficient (r) \\
\hline Heart & $A=0.0967 C+0.0072$ & $0.05-10$ & $\mathrm{r}=0.9997$ \\
\hline Kidney & $A=0.0866 C+0.0083$ & $0.2-10$ & $\mathrm{r}=0.9996$ \\
\hline Brain & $\mathrm{A}=0.0788 \mathrm{C}+0.0071$ & $0.05-10$ & $\mathrm{r}=0.9997$ \\
\hline Stomach & $\mathrm{A}=0.0732 \mathrm{C}+0.0304$ & $0.05-5$ & $\mathrm{r}=0.9994$ \\
\hline Plasma & $A=0.1017 C-0.0037$ & $0.05-10$ & $\mathrm{r}=0.9995$ \\
\hline Liver & $\mathrm{A}=0.0657 \mathrm{C}+0.0003$ & $0.2-5$ & $\mathrm{r}=0.9991$ \\
\hline Spleen & $A=0.0584 C+0.0123$ & $0.05-10$ & $\mathrm{r}=0.9996$ \\
\hline Lung & $\mathrm{A}=0.059 \mathrm{C}+0.2118$ & $0.75-300$ & $\mathrm{r}=0.9992$ \\
\hline
\end{tabular}

\subsubsection{Accuracy and Precision}

Both the accuracy and precision of analysis method were determined by using three QC samples at low, medium and high concentrations. Besides, the precision needed to be calculated the relative standard deviation (RSD) and the results were shown in Table 2. The RSD values of intra-and inter-day for the plasma and tissues were from 4.19 to 10.84 and from 4.37 to 10.93 , respectively, which were less than 15 , revealed that the precision of the analytical method was high.

The accuracy of plasma and tissue samples ranged from $81.6 \%$ to $95.2 \%$ and $80.8 \%$ to $98.4 \%$, respectively, which indicated that there was no interference from endogenous components.

Table 2. Intra- and inter-day accuracy and precision data for baicalin in rabbit plasma and tissues ${ }^{\text {a }}$.

\begin{tabular}{|c|c|c|c|c|c|c|c|}
\hline \multirow{2}{*}{ Samples } & \multirow{2}{*}{$\begin{array}{c}\text { Added } \\
\text { Concentration }\end{array}$} & \multicolumn{3}{|c|}{ Intra-Day } & \multicolumn{3}{|c|}{ Inter-Day } \\
\hline & & $\begin{array}{c}\text { Measured } \\
\text { Concentration }\end{array}$ & $\begin{array}{c}\text { Accuracy } \\
(\%)\end{array}$ & $\begin{array}{l}\text { (RSD) } \\
(\%)\end{array}$ & $\begin{array}{c}\text { Measured } \\
\text { Concentration }\end{array}$ & $\begin{array}{c}\text { Accuracy } \\
(\%)\end{array}$ & $\begin{array}{l}\text { (RSD) } \\
(\%)\end{array}$ \\
\hline \multirow{3}{*}{ Plasma } & 0.0525 & 0.045 & 85.2 & 6.91 & 0.048 & 90.9 & 6.24 \\
\hline & 4.7500 & 4.223 & 88.3 & 9.06 & 4.518 & 95.2 & 8.37 \\
\hline & 9.5000 & 7.747 & 81.6 & 8.69 & 8.527 & 89.5 & 9.64 \\
\hline \multirow{3}{*}{ Heart } & 0.0525 & 0.044 & 83.8 & 4.42 & 0.046 & 87.4 & 4.37 \\
\hline & 4.7500 & 4.015 & 84.5 & 9.65 & 4.346 & 91.5 & 9.94 \\
\hline & 9.5000 & 8.912 & 93.8 & 6.75 & 7.681 & 80.6 & 7.47 \\
\hline \multirow{3}{*}{ Liver } & 0.210 & 0.191 & 91.3 & 6.52 & 0.183 & 87.2 & 6.97 \\
\hline & 2.375 & 1.926 & 81.1 & 10.24 & 2.094 & 88.4 & 10.81 \\
\hline & 4.750 & 3.837 & 80.7 & 9.57 & 4.025 & 84.7 & 9.18 \\
\hline \multirow{3}{*}{ Spleen } & 0.0525 & 0.047 & 88.5 & 7.97 & 0.048 & 90.4 & 7.24 \\
\hline & 4.7500 & 4.126 & 86.6 & 5.46 & 4.388 & 92.7 & 5.02 \\
\hline & 9.5000 & 8.005 & 84.2 & 9.11 & 7.732 & 81.3 & 9.48 \\
\hline \multirow{3}{*}{ Lung } & 0.8 & 0.663 & 82.9 & 4.19 & 0.649 & 80.8 & 4.74 \\
\hline & 142.5 & 132.245 & 92.5 & 5.64 & 119.272 & 83.7 & 5.38 \\
\hline & 285.0 & 232.275 & 81.4 & 8.84 & 251.655 & 88.6 & 9.17 \\
\hline
\end{tabular}


Table 2. Cont.

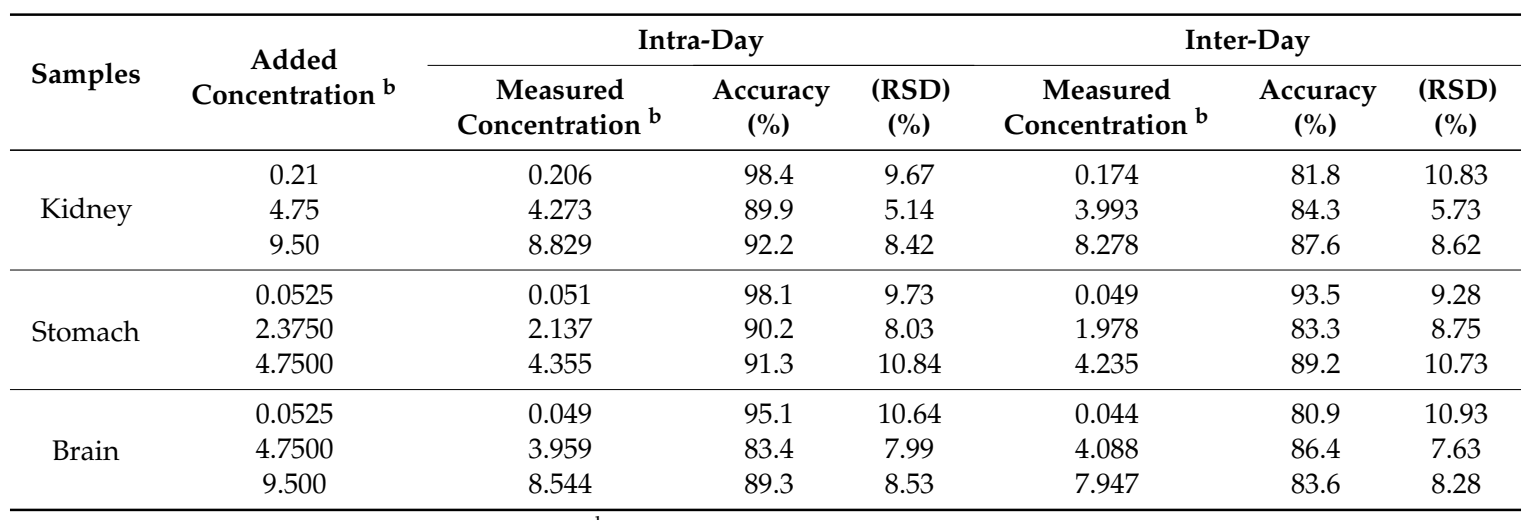

${ }^{a}$ The values are arithmetic means, $n=3{ }^{\text {b }}$ The unit of drug concentration in plasma: $\mu \mathrm{g} / \mathrm{mL}$; The unit of drug concentration in tissue: $\mu \mathrm{g} / \mathrm{g}$.

\subsubsection{Extraction Recovery}

Baicalin is a flavanoid glycoside with relatively high polarity and poor solubility. Importantly, it has characteristics of easy biological degradation and temperature- and $\mathrm{pH}$-dependent stability. Several studies reported in the literature have indicated that it is necessary to maintain a stable acidic environment in biosamples for the processing and storage of baicalin [25,26]. At present, the pretreatment methods of baicalin in plasma, urine and serum mainly include solid-phase extraction (SPE), protein precipitation (PPT) and liquid-liquid extraction (LLE) [22]. Because baicalin is an unstable compound, the relatively long column activation time, sample loading time and elution time of SPE resulted in its degradation in the biosamples to some extent. Although PPT has high extraction recovery for many compounds and easy sample manipulation, the absolute recovery of baicalin obtained from rat plasma by the PPT pretreatment method was found to be only $66.1 \%$ [23]. Among these pretreatment methods, LLE using ethyl acetate or acetone as extraction regent was the most frequently used method to process baicalin biosamples with absolute recoveries ranging from $60 \%$ to $70 \%[27,28]$. In the preliminary study, the LLE method reported above was used, but it led to low extraction recovery $(<60 \%)$ in rabbit tissues and the samples contained endogenous substances which influenced with the determination of baicalin and IS in rabbit biosamples. According to [29], on the basis of LLE, the use of inorganic salts may both significantly increase the extraction efficiency of the drug from aqueous phase and further purify the biosamples. Therefore, in the present study, the effect of $\mathrm{pH}$ values (3.5, 4.5 and 5.5) and concentration ( $0.5 \mathrm{M}, 1 \mathrm{M}$ and $2 \mathrm{M})$ of ammonium acetate buffer as inorganic salt on the extraction recovery of baicalin in biosamples was investigated using the same volume of acetonitrile as in the protein precipitation. The results showed that the optimal pretreatment method composed of $250 \mu \mathrm{L}$ of ammonium acetate buffer ( $\mathrm{pH} 3.5 ; 1 \mathrm{M}$ ) and $3 \mathrm{~mL}$ of acetonitrile could not only afford high extraction recoveries of baicalin in biosamples that ranged from $81.5 \%$ to $88.3 \%$ for plasma, from $73.1 \%$ to $93.2 \%$ for tissues, respectively (Table 3), but also remove the interfering substances in plasma or tissue samples (Figures 2-9).

Table 3. Extraction recovery of baicalin in rabbit plasma and tissues ${ }^{\text {a }}$.

\begin{tabular}{cccc}
\hline Samples & Added Concentration $(\mu \mathbf{g} / \mathbf{m L} \text { or } \mu \mathbf{g} / \mathbf{g})^{\mathbf{b}}$ & Extraction Recovery $(\mu \mathbf{g} / \mathbf{m L ~ o r ~} \mu \mathbf{g} / \mathbf{g})^{\mathbf{b}}$ & RSD (\%) \\
\hline \multirow{3}{*}{ Plasma } & 0.0525 & 85.7 & 2.51 \\
& 4.75 & 88.3 & 9.28 \\
& 9.5 & 81.5 & 8.87 \\
\multirow{3}{*}{ Heart } & 0.0525 & 87.9 & 1.08 \\
& 4.75 & 82.7 & 1.58 \\
& 9.5 & 86.9 & 7.14 \\
\hline \multirow{3}{*}{ Kidney } & 0.21 & 78.7 & 9.73 \\
& 4.75 & 93.2 & 9.51 \\
& 9.5 & 80.3 & 5.84 \\
\hline
\end{tabular}


Table 3. Cont.

\begin{tabular}{|c|c|c|c|}
\hline Samples & Added Concentration $(\mu \mathrm{g} / \mathrm{mL} \text { or } \mu \mathrm{g} / \mathrm{g})^{b}$ & Extraction Recovery $(\mu \mathrm{g} / \mathrm{mL} \text { or } \mu \mathrm{g} / \mathrm{g})^{b}$ & RSD (\%) \\
\hline \multirow{3}{*}{ Brain } & 0.0525 & 81.7 & 3.38 \\
\hline & 4.75 & 86.4 & 2.12 \\
\hline & 9.5 & 79.2 & 3.03 \\
\hline \multirow{3}{*}{ Stomach } & 0.0525 & 87.2 & 9.89 \\
\hline & 2.375 & 81.8 & 2.75 \\
\hline & 4.75 & 94.6 & 6.68 \\
\hline \multirow{3}{*}{ Liver } & 0.21 & 92.3 & 8.16 \\
\hline & 2.375 & 80.7 & 5.47 \\
\hline & 4.75 & 73.1 & 8.58 \\
\hline \multirow{3}{*}{ Spleen } & 0.0525 & 91.9 & 9.35 \\
\hline & 4.75 & 78.3 & 8.07 \\
\hline & 9.5 & 81.5 & 3.21 \\
\hline \multirow{3}{*}{ Lung } & 0.8 & 93.2 & 1.68 \\
\hline & 142.5 & 9.9 & 3.85 \\
\hline & 285.0 & 87.1 & 8.65 \\
\hline
\end{tabular}

\subsubsection{Stability}

The stability of baicalin in rabbit plasma or tissues with QC samples was investigated and the results are presented in Table 4 . The relative error (RE) of baicalin between the initial concentrations and the concentration following five freeze-thaw cycles ranged from $-14.7 \%$ to $7.0 \%$, at $-20{ }^{\circ} \mathrm{C}$ for 15 days ranged from $-14.3 \%$ to $-4.1 \%$, and post-preparative stability after $12 \mathrm{~h}$ ranged from $-14.3 \%$ to $4.8 \%$, respectively, which were less than $15 \%$. Hence, it suggested that baicalin was stable in rabbit plasma and tissues.

Table 4. Stability of baicalin in rabbit plasma and tissues with QC samples determined by LC-UV a

\begin{tabular}{|c|c|c|c|c|c|c|c|}
\hline \multirow[b]{2}{*}{ Samples } & \multirow[b]{2}{*}{$\begin{array}{c}\text { Added } \\
\text { Concentration } \\
(\mu \mathrm{g} / \mathrm{mL} \text { or } \mu \mathrm{g} / \mathrm{g})^{\mathrm{b}}\end{array}$} & \multicolumn{2}{|c|}{ Freeze-Thaw Stability } & \multicolumn{2}{|c|}{ Storage Stability } & \multicolumn{2}{|c|}{ Post-Preparative Stability } \\
\hline & & $\begin{array}{c}\text { Measured } \\
\text { Concentration } \\
(\mu \mathrm{g} / \mathrm{mL} \text { or } \mu \mathrm{g} / \mathrm{g})^{\mathrm{b}}\end{array}$ & $\begin{array}{c}\text { Relative } \\
\text { Error } \\
(\%)\end{array}$ & $\begin{array}{c}\text { Measured } \\
\text { Concentration } \\
(\mu \mathrm{g} / \mathrm{mL} \text { or } \mu \mathrm{g} / \mathrm{g})^{\mathrm{b}}\end{array}$ & $\begin{array}{l}\text { Relative } \\
\text { Error } \\
(\%)\end{array}$ & $\begin{array}{c}\text { Measured } \\
\text { Concentration } \\
(\mu \mathrm{g} / \mathrm{mL} \text { or } \mu \mathrm{g} / \mathrm{g})^{\mathrm{b}}\end{array}$ & $\begin{array}{c}\text { Relative } \\
\text { Error } \\
(\%)\end{array}$ \\
\hline \multirow{3}{*}{ Plasma } & 0.0525 & 0.047 & -10.5 & 0.049 & -6.7 & 0.045 & -14.3 \\
\hline & 4.75 & 4.138 & -12.9 & 4.258 & -10.4 & 4.371 & -8.0 \\
\hline & 9.5 & 8.362 & -12.0 & 8.139 & -14.3 & 8.697 & -8.5 \\
\hline \multirow{3}{*}{ Heart } & 0.0525 & 0.048 & -8.6 & 0.045 & -14.3 & 0.047 & -10.5 \\
\hline & 4.75 & 4.154 & -12.5 & 4.123 & 13.2 & 4.472 & -5.9 \\
\hline & 9.5 & 8.118 & -14.5 & 8.767 & -7.7 & 8.93 & -6.0 \\
\hline \multirow{3}{*}{ Kidney } & 0.21 & 0.18 & -14.3 & 0.18 & -14.3 & 0.19 & -9.5 \\
\hline & 4.75 & 4.164 & -12.3 & 4.109 & -13.5 & 4.497 & -5.3 \\
\hline & 9.5 & 8.569 & -9.8 & 8.895 & -6.4 & 9.154 & -3.6 \\
\hline \multirow{3}{*}{ Brain } & 0.0525 & 0.046 & -12.4 & 0.048 & -8.6 & 0.049 & -6.7 \\
\hline & 4.75 & 4.272 & -10.1 & 4.172 & -12.2 & 4.625 & -2.6 \\
\hline & 9.5 & 8.763 & -7.8 & 8.863 & -6.7 & 9.29 & -2.2 \\
\hline \multirow{3}{*}{ Stomach } & 0.0525 & 0.045 & -14.3 & 0.048 & -8.6 & 0.047 & -10.5 \\
\hline & 2.375 & 2.149 & -9.5 & 2.218 & -6.6 & 2.195 & -7.6 \\
\hline & 4.75 & 4.056 & -14.6 & 4.476 & -5.8 & 4.556 & -4.1 \\
\hline \multirow{3}{*}{ Liver } & 0.21 & 0.193 & -8.1 & 0.182 & -13.3 & 0.22 & 4.8 \\
\hline & 2.375 & 2.068 & -12.9 & 2.122 & -10.7 & 2.389 & 0.6 \\
\hline & 4.75 & 4.054 & -14.7 & 4.365 & -8.1 & 4.891 & 3.0 \\
\hline \multirow{3}{*}{ Spleen } & 0.0525 & 0.046 & -12.4 & 0.047 & -10.5 & 0.053 & 1.0 \\
\hline & 4.75 & 3.956 & -16.7 & 4.556 & -4.1 & 4.689 & -1.3 \\
\hline & 9.5 & 8.252 & -13.1 & 8.589 & -9.6 & 9.138 & -3.8 \\
\hline \multirow{3}{*}{ Lung } & 0.8 & 0.744 & -7.0 & 0.72 & -10.0 & 0.84 & 5.0 \\
\hline & 142.5 & 125.828 & -11.7 & 130.28 & -8.6 & 135.66 & -4.8 \\
\hline & 285 & 256.35 & -10.1 & 265.79 & -6.7 & 271.45 & -4.8 \\
\hline
\end{tabular}

${ }^{a}$ The values are arithmetic means, $n=3{ }^{\mathrm{b}}$ The unit of drug concentration in plasma: $\mu \mathrm{g} / \mathrm{mL}$; The unit of drug concentration in tissues: $\mu \mathrm{g} / \mathrm{g}$. 


\subsection{Pharmacokinetics and Tissue Distribution Study}

\subsubsection{Plasma Pharmacokinetics Study}

The LC-UV analytical method developed in this study was used to determine the plasma concentration of baicalin in rabbits after a single intravenous administration of baicalin-loaded liposomes and its injectable solution at a dose of $10 \mathrm{mg} / \mathrm{kg}$ to rabbits. The mean plasma drug concentration-time profile and the main pharmacokinetic parameters are shown in Figure 10 and Table 5, respectively. It can be seen from the plasma drug concentration-time profile that the drug concentration in plasma decreased rapidly and was detectable up to at least $24 \mathrm{~h}$. As far as pharmacokinetic parameters, the distribution phase $\left(t_{1 / 2 \alpha}\right)$ half-lifes was $0.038 \mathrm{~h}$ and the half-life of the elimination phase $\left(t_{1 / 2 \beta}\right)$ was $1.02 \mathrm{~h}$ after intravenous administration of baicalin-loaded liposomes to rabbits, which were shorter than those of its injectable solution $(0.141 \mathrm{~h}$ and $3.88 \mathrm{~h}$, respectively). The plasma clearance $\left(\mathrm{CL}_{\mathrm{z}}\right)$ and the volume of distribution $\left(\mathrm{V}_{\mathrm{z}}\right)$ of baicalin-loaded liposomes $(3.51 \mathrm{~L} / \mathrm{h} / \mathrm{kg}$ and $51.77 \mathrm{~L} / \mathrm{kg})$ were significantly higher than those of its injectable solution (1.34 L/h/kg and $10.27 \mathrm{~L} / \mathrm{kg})$.

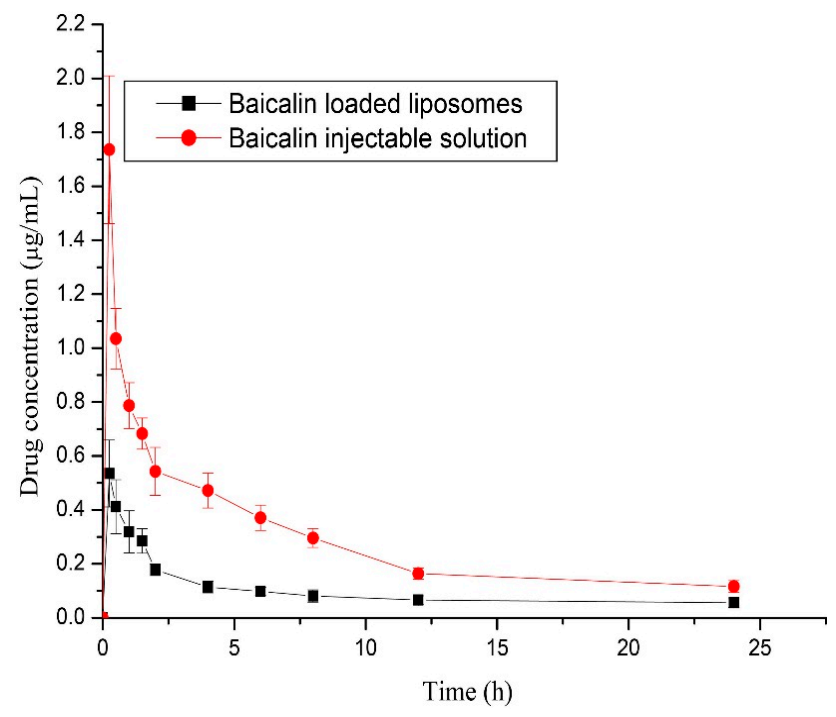

Figure 10. Mean plasma drug concentration-time profile of baicalin determined by LC-UV method via intravenous administration of baicalin loaded liposomes and its injectable solution at a dose of $10 \mathrm{mg} / \mathrm{kg}$ to rabbits. Each point represents the mean $+\mathrm{SD}(n=5)$.

Table 5. The comparative pharmacokinetic parameters via intravenous administration of baicalin loaded liposomes and its injectable solution at a dose of $10 \mathrm{mg} / \mathrm{kg}$ to rabbits. Each point represents the mean $+\mathrm{SD}(n=5)$.

\begin{tabular}{ccccccc}
\hline Samples & $\mathbf{t}_{\mathbf{1} / \mathbf{2} \alpha}(\mathbf{h})$ & $\mathbf{t}_{\mathbf{1} / \mathbf{2} \beta}$ & $\mathrm{C}_{\max }(\mu \mathrm{g} / \mathrm{mL})$ & $\mathrm{AUC}_{(\mathbf{0 - 2 4 h})}(\mathbf{m g} / \mathrm{L} \cdot \mathbf{h})$ & $\mathrm{CLz}(\mathrm{L} / \mathrm{h} / \mathbf{k g})$ & $\mathrm{Vz}(\mathrm{L} / \mathbf{k g})$ \\
\hline Baicalin liposomes & 0.038 & 1.02 & $0.535^{*}$ & $2.42^{*}$ & 3.51 & 51.77 \\
Baicalin injection & 0.141 & 3.88 & 1.736 & 7.07 & 1.34 & 10.27 \\
\hline
\end{tabular}

${ }^{*} p<0.01$ compared with baicalin injection.

The area under the curve $\left(\mathrm{AUC}_{(0-24 \mathrm{~h})}\right)$ of the liposomal formulation was about 3-fold lower than that of injectable formulation, suggesting that the liposome carrier could increase the biodistribution of baicalin in tissues.

\subsubsection{Tissue Distribution Study}

The drug concentration in plasma and tissues was determined by the developed LC-UV analytical method and the biodistribution behavior of baicalin at $0.25 \mathrm{~h}$ after a single intravenous administration 
of baicalin-loaded liposomes and its injectable solution is presented in Figure 11. It can be seen from Figure 11 that the liposome carrier significantly altered the tissue distribution characteristics of baicalin in rabbits in comparison with its injectable solution. After intravenous administration of liposomal baicalin, the drug concentration in the lungs was the highest $(15.693 \pm 0.839 \mu \mathrm{g} / \mathrm{g})$ among all tissues or plasma, that is, the drug concentration decreased in main organ tissues in the following order: lung $>$ liver $>$ kidney $>$ spleen. When administered with its injectable solution, drug concentration decreased in the main organ tissues in the following order: kidney $>$ lung $>$ liver $>$ spleen. Baicalin concentration in the lungs after intravenous administration of baicalin-loaded liposomes was increased from $5.627 \pm 0.697 \mu \mathrm{g} / \mathrm{g}$ to $15.693 \pm 0.839 \mu \mathrm{g} / \mathrm{g}$ (2.789-fold) in comparison with its injectable solution.

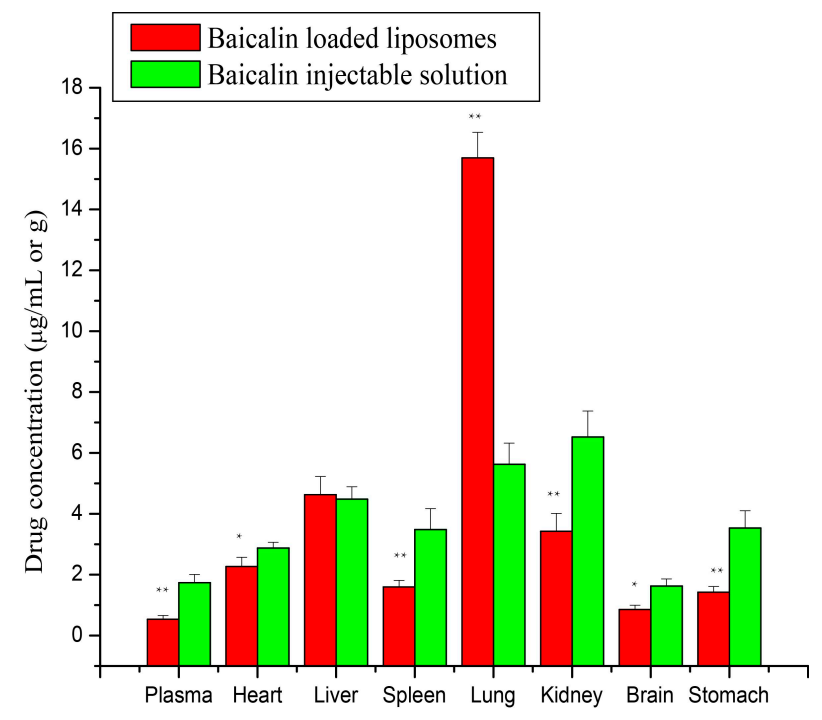

Figure 11. Distribution in plasma and tissues after via intravenous administration of baicalin loaded liposomes and its injectable solution at a dose of $10 \mathrm{mg} / \mathrm{kg}$ to rabbits. Each point represents the mean $+\mathrm{SD}(n=5) .{ }^{* *} p<0.01$ compared with baicalin injection; ${ }^{*} p<0.05$ compared with baicalin injection.

From the clinical point of view, the biodistribution of the liposomes is an important parameter. The biodistribution behavior of the liposome carrier mainly depends on its physiochemical characterization including particle size, zeta potential, membrane lipid component and steric stabilization [30]. Many studies have indicated that liposomes mostly accumulate in the organs of the reticuloendothelial system such as liver, spleen and lung within the first 15-30 min after intravenous administration of a liposomal formulation [31]. Therefore, it demonstrated that the liposome carrier could deliver baicalin mainly into lung tissue after intravenous administration.

\section{Materials and Methods}

\subsection{Materials and Animals}

The crude baicalin was obtained from Xinxiang Bokai Bio-Technology Co., Ltd. (Henan, China). The baicalin reference sample used in the analysis was provided by the National Institute for Food and Drug Control of China (Beijing, China). The internal standard rutin was obtained from Chengdu Mansite Pharmaceutical Co., Ltd. (Sichuan, China). Phospholipon 90H (HSPC) was obtained from Shanghai Toshisun Bio-Technology Co., Ltd. (Shanghai, China). Citric acid (injection grade), carbonic acid monosodium salt $\left(\mathrm{NaHCO}_{3}\right)$, Tween-80 (injection grade), anhydrous alcohol and ammonium acetate were purchased from Luzhou Juhe Chemical Co., Ltd., (Luzhou, China). Acetonitrile and methanol (HPLC grade) were obtained from Chengdu Jinghong Co., Ltd., (Chengdu, China). 0.9\% Sodium chloride injection was supplied from the First Affiliated Hospital of Southwest Medical University (Luzhou, China). Ultrapure water used in this study was prepared in our experiments. New Zealand white rabbits (weight $1.5-2.0 \mathrm{~kg}$ ) were obtained from the Laboratory Animal Center of 
Southwest Medical University (Luzhou, China). The rabbits were maintained in a temperatureand moisture-controlled $\left(20 \pm 2{ }^{\circ} \mathrm{C}\right.$ and $55 \% \pm 10 \%$, respectively) room with a $12 \mathrm{~h}$ light-dark cycle, and allowed free access to food and water except when fasted for $12 \mathrm{~h}$ before experiments. The experimental protocol was approved by the Southwest Medical University Animal Ethical Experimentation Committee (No: 2013002).

\subsection{Preparation of Baicalin Lposomes}

Baicalin-loaded liposomes used in this study were prepared by the effervescent dispersion technique. Briefly, baicalin (100 mg), HSPC (100 mg), Tween-80 (50 mg) and citric acid (50 mg) were weighed and dissolved in an appropriate volume of ethanol. The solution was added dropwise to aqueous $\mathrm{NaHCO}_{3}$ solution $(0.5 \%, w / v)$ containing mannitol $(5.0 \%, w / v)$ at $15-20^{\circ} \mathrm{C}$ with continuous stirring. The mixture solution was continually stirred until it became cheese-like. Finally the cheese-like products were lyophilized and stored at $2-8^{\circ} \mathrm{C}$ for further study.

\subsection{Equipment and LC-UV Conditions}

The LC-UV system used for determination of baicalin concentration in rabbit plasma and tissues in this study was an Ultimate 3000 series chromatographic system (Dionex, MA, USA) equipped with an Inertsil ODS-SP reverse-phase C18 column $(4.6 \times 250 \mathrm{~mm}, 5 \mu \mathrm{m})$ protected by a Phenomenex C18 guard column $(4.0 \mathrm{~mm} \times 3.0 \mathrm{~mm}, 5 \mu \mathrm{m})$ (Torrance, CA, USA) with the column temperature maintained at $35{ }^{\circ} \mathrm{C}$. UV absorption was set at $278 \mathrm{~nm}$. The mobile phase consisted of the mixture of methanol and acetonitrile $(1: 1, v / v)(\mathrm{A})$ and $0.4 \%(v / v)$ aqueous phosphoric acid (B). The gradient began with $85 \%$ eluent B for $1 \mathrm{~min}$, decreased linearly to $30 \%$ eluent B for $13 \mathrm{~min}$. The gradient was then returned to initial condition for $1 \mathrm{~min}$ and was maintained in this condition for $1 \mathrm{~min}$. The flow rate was $1.0 \mathrm{~mL} / \mathrm{min}$ and $20 \mu \mathrm{L}$ of sample solution was injected into LC-UV system.

\subsection{Preparation of Calibration Standards and Quality Control Samples}

Blood and tissue samples were obtained from experimental rabbits and stored at $-20{ }^{\circ} \mathrm{C}$ until baicalin was assayed. $0.5 \mathrm{~mL}$ of blank plasma or tissue homogenate suspension was mixed with $50 \mu \mathrm{L}$ of various known concentrations of baicalin standard working solutions and $50 \mu \mathrm{L}$ of rutin solution $(80.0 \mu \mathrm{g} / \mathrm{mL}$ in methanol) as the internal standard to obtain a series of baicalin standard solutions at concentrations ranged from 0.05 to $10 \mu \mathrm{g} / \mathrm{mL}$ for plasma, from 0.05 to $10 \mu \mathrm{g} / \mathrm{g}$ for heart, brain and spleen, from 0.2 to $10 \mu \mathrm{g} / \mathrm{g}$ for kidney, from 0.05 to $5 \mu \mathrm{g} / \mathrm{g}$ for stomach, from 0.2 to $5 \mu \mathrm{g} / \mathrm{g}$ for liver and from 0.75 to $300 \mu \mathrm{g} / \mathrm{g}$ for lung. Quality control (QC) samples were prepared by blank plasma or blank tissue homogenate suspension at low, medium and high baicalin concentrations.

\subsection{Validation of Analysis Method}

In order to confirm the capability of the method to satisfy the requirements of the application, the analytical method was validated in terms of the selectivity, linearity, precision, accuracy, extraction recovery and stability according to the bioanalytical method validation guidance from the U.S. Food and Drug Administration (2001 version).

The selectivity of the method was determined by comparing the chromatography of blank biosamples, blank biosamples spiked with baicalin and (or) IS, and biosamples following intravenous administration of baicalin-loaded liposomes to ensure no interference. Because quantitative analytical results are greatly affected by the quality of the calibration curve, seven different baicalin concentrations with the fixed IS concentration in blank rabbits plasma or tissue homogenate suspension were used in this study and the standard curves were obtained by plotting the peak area ratios $(R)$ of baicalin and IS against the corresponding baicalin concentration (C). Intra-day and inter-day accuracy and precision were investigated by determining QC samples at low, medium and high concentration on the same day and on three separate days. The extraction recoveries of baicalin at three QC concentrations were calculated by comparing the peak area of baicalin in extracted biosamples with those obtained by directly determining baicalin standard solutions at the same concentration. The stability of baicalin in 
rabbit plasma and tissue samples was investigated at three QC concentrations. For long-term stability, biosamples were kept at $-20^{\circ} \mathrm{C}$ for 15 days; freeze-thaw stability was tested through five freeze-thaw cycles on samples that were frozen at $-20^{\circ} \mathrm{C}$ and thawed at room temperature on days $0,2,4,6,8$; and post-preparative stability was investigated by reanalyzing QC samples at five time points for $12 \mathrm{~h}$.

\subsection{Application in Pharmacokinetics and Tissue Distribution Study}

The developed LC-UV method was applied to quantify the plasma or tissue drug concentration of baicalin. For a pharmacokinetics study, baicalin-loaded liposomes and its injectable formulation were injected through the ear vein of rabbits at a dose of $10 \mathrm{mg}$ baicalin per $\mathrm{kg}$ body weight. Blood samples $(1.5 \mathrm{~mL})$ were collected from the marginal ear vein into heparinized centrifuge tubes just before dosing $(0 \mathrm{~h})$ and after at $0.25,0.5,1,1.5,2,4,6,8,12$ and $24 \mathrm{~h}$. The blood samples were immediately centrifuged at $5000 \mathrm{rpm}$ for $5 \mathrm{~min}$ to separate the plasma and stored at $-20{ }^{\circ} \mathrm{C}$ until analysis.

For the tissue distribution study, baicalin-loaded liposomes and its injectable formulation were administered to five experimental rabbits intravenously with a single dose equivalent to $10 \mathrm{mg}$ baicalin per $\mathrm{kg}$ body weight. The rabbits were sacrificed at $0.25 \mathrm{~h}$ after intravenous administration. Heart, liver, spleen, lung, kidney, stomach and brain were sampled immediately and washed with $0.9 \%$ saline solution. After surface water was dried, $2 \mathrm{~g}$ of tissue sample was homogenized with $4 \mathrm{~mL}$ methanol and stored at $-20^{\circ} \mathrm{C}$ until analysis for baicalin content.

Plasma or tissue homogenate samples $(0.5 \mathrm{~mL})$ were mixed with $50 \mu \mathrm{L}$ of rutin internal standard solution containing IS $(80.0 \mu \mathrm{g} / \mathrm{mL}$ in methanol) and $250 \mu \mathrm{L}$ of ammonium acetate buffer (pH 3.5, $1 \mathrm{M})$ and vortexed for $3 \mathrm{~min}$, and then $3 \mathrm{~mL}$ of acetonitrile was added to the solution by vortex mixing for $5 \mathrm{~min}$. After centrifugation at 10,000 rpm for $10 \mathrm{~min}$, the clear supernatant was collected and evaporated to dryness under a nitrogen gas stream at $40{ }^{\circ} \mathrm{C}$. The dry sample was reconstituted with $200 \mu \mathrm{L}$ of mobile phase and vortex-mixed, and centrifuged at 10,000 rpm for $10 \mathrm{~min}$. Then $20 \mu \mathrm{L}$ of the clear supernatant was injected into chromatographic system.

\subsection{Data Analysis}

The pharmacokinetic parameters including the area under the plasma drug concentration-time curve $\left(\mathrm{AUC}_{0-\mathrm{t}}\right)$, the half-lives of distribution phase $\left(\mathrm{t}_{1 / 2 \alpha}\right)$, the half-lives of elimination phase $(\mathrm{t} 1 / 2 \beta)$, apparent volume of distribution $(\mathrm{Vz})$, clearance rate $(\mathrm{CLz})$ and the peak concentration (Cmax) were calculated by the pharmacokinetical software program DAS 2.0 (Mathematical Pharmacology Professional Committee of China, Shanghai, China). All results were expressed as the mean \pm standard deviation (SD) and statistically significant difference between the pharmacokinetic data of baicalin loaded liposomes and its injection as control was evaluated using two-tailed $t$ test. The level of significant difference was set at $p<0.05$.

\section{Conclusions}

Baicalin and the internal standard, rutin were extracted from biosamples using acetonitrile as protein precipitation reagent after pretreatment with ammonium acetate buffer ( $\mathrm{pH} 3.5,1 \mathrm{M}$ ) to obtain chromatographically pure peaks and high extraction recovery. Therefore, the developed reverse-phase LC-UV analytical method for the determination of baicalin in rabbit plasma and tissues offers excellent selectivity, linearity, accuracy, precision, recovery and a short running time. The validated LC-UV assay method has been successfully applied to pharmacokinetic and tissue distribution studies of baicalin after intravenous administration of baicalin-loaded liposomes and its injectable solution to rabbits. In fact, the assay method is also suitable for quantitative determination of baicalin in biosamples in preclinical and clinical experimental phase studies of baicalin-loaded liposomes. Interestingly, after intravenous administration of baicalin-loaded liposomes, the liposome carrier significantly altered the pharmacokinetics and biodistribution behavior of baicalin in rabbits in comparison with its injectable solution and showed greatly increased drug concentrations in the lungs. It suggested that baicalin-loaded liposomes have good lung targeting characteristics and advantages for the treatment of lung diseases. 
Acknowledgments: This study was financially supported by the National Natural Science Foundation of China (81101678, 81341124), Science and Technology Support Project of Sichuan Province (2013SZZ006, 2014SZ0071, 2014FZ0105), the Joint Fund of Sichuan Province, Luzhou City and Sichuan Medical University (14JC0134, 14ZC0026, 14ZC0066), the Joint Fund of Luzhou City and Sichuan Medical University (2013LZLY-K80, 2015LZCYD-S09(4/8)), the Key Program of the Scientific Research Foundation of the Education Department of Sichuan Province (12ZZ020; 12ZB066), the Scientific Research Foundation of the Administration of Traditional Chinese Medicine of Sichuan Province (2012-F-026), the Scientific Research Foundation of the Health Bureau of Sichuan Province [130270, 130269] and the Key Program of the Scientific Research Foundation of Bureau of Science and Technology of Luzhou City (2013-S-47(17/20)).

Author Contributions: Yumeng Wei and Ling Zhao designed the research. Yumeng Wei and Chao Pi performed the experiments; Gang Yang , Xiaoming Xiong, Yongshu Lan, Hongru Yang, Yang Zhou, Yun Ye, Yonggen Zou, Wenwu Zheng contributed part reagents; Yumeng Wei and Ling Zhao analyzed the data and wrote the manuscript.

Conflicts of Interest: The authors declare no conflict of interest.

\section{References}

1. Pan, T.L.; Wang, P.W.; Huang, C.H.; Leu, Y.L.; Wu, T.H.; Wu, Y.R.; You, J.S. Herbal formula, Scutella-riae radix and Rhei rhizoma attenuate dimethylnitrosamine-induced liver fibrosis in a rat model. Sci. Rep. 2015, 5, 11734-11741. [CrossRef] [PubMed]

2. Cui, L.; Feng, L.; Zhang, Z.H.; Jia, X.B. The anti-inflammation effect of baicalin on experimental colitis through inhibiting TLR4/NF-кB pathway activation. Int. Immunopharmacol. 2014, 23, 294-303. [CrossRef] [PubMed]

3. Wang, S.C.; Chen, S.F.; Lee, Y.M.; Chuang, C.L.; Bau, D.T.; Lin, S.S. Baicalin scavenges reactive oxygen species and protects human keratinocytes against UVC-induced cytotoxicity. Vivo 2013, 27, 707-714.

4. Lixuan, Z.; Jingcheng, D.; Wenqin, Y.; Jianhua, H.; Baojun, L.; Xiaotao, F. Baicalin attenuates inflammation by inhibiting NF-kB activation in cigarette smoke induced inflammatory models. Pulm. Pharmacol. Ther. 2010, 23, 411-419. [CrossRef] [PubMed]

5. Chan, F.L.; Choi, H.L.; Chen, Z.Y.; Chan, P.S.; Huang, Y. Induction of apoptosis in prostate cancer cell lines by a flavonoid, baicalin. Cancer Lett. 2000, 160, 219-228. [CrossRef]

6. Srinivas, N.R. Baicalin, an emerging multi-therapeutic agent: Pharmacodynamics, pharmacokinetics, and considerations from drug development perspectives. Xenobiotica 2010, 40, 357-367. [CrossRef] [PubMed]

7. Li, J.; Zhang, M.; Chao, J.; Shuang, S. Preparation and characterization of the inclusion complex of Baicalin (BG) with beta-CD and HP- $\beta-C D$ in solution: An antioxidant ability study. Spectrochim. Acta A Mol. Biomol. Spectrosc. 2009, 73, 752-756. [CrossRef] [PubMed]

8. Zhao, L.; Wei, Y.; Huang, Y.; He, B.; Zhou, Y.; Fu, J. Nanoemulsion improves the oral bioavailability of baicalin in rats: In vitro and in vivo evaluation. Int. J. Nanomed. 2013, 8, 3769-3779. [CrossRef] [PubMed]

9. Liu, Z.; Zhang, L.; He, Q.; Liu, X.; Okeke, C.I.; Tong, L.; Guo, L.; Yang, H.; Zhang, Q.; Zhao, H.; et al. Effect of Baicalin-loaded PEGylated cationic solid lipid nanoparticles modified by OX26 antibody on regulating the levels of baicalin and amino acids during cerebral ischemia-reperfusion in rats. Int. J. Pharm. 2015, 489, 131-138. [CrossRef] [PubMed]

10. Li, N.; Je, Y.J.; Yang, M.; Jiang, X.H.; Ma, J.H. Pharmacokinetics of baicalin-phospholipid complex in rat plasma and brain tissues after intranasal and intravenous administration. Pharmazie 2011, 66, 374-377. [PubMed]

11. Wu, J.; Chen, D.; Zhang, R. Study on the bioavailability of baicalin-phospholipid complex by using HPLC. Biomed. Chromatogr. 1999, 13, 493-495. [CrossRef]

12. Li, B.; He, M.; Li, W.; Luo, Z.; Guo, Y.; Li, Y.; Zang, C.; Wang, B.; Li, F.; Li, S.; et al. Dissolution and pharmacokinetics of baicalin-polyvinylpyrrolidone coprecipitate. J. Pharm. Pharmacol. 2013, 65, 1670-1678. [CrossRef] [PubMed]

13. Du, G.; Han, G.; Zhang, S.; Lin, H.; Wu, X.; Wang, M.; Ji, L.; Lu, L.; Yu, L.; Liang, W. Baicalin sup-presses lung carcinoma and lung metastasis by SOD mimic and HIF-1alpha inhibition. Eur. J. Pharmacol. 2010, 630, 121-130. [CrossRef] [PubMed]

14. Li, Z.; Xia, X.; Zhang, S.; Zhang, A.; Bo, W.; Zhou, R. Up-regulation of Toll-like receptor 4 was suppressed by emodin and baicalin in the setting of acute pancreatitis. Biomed. Pharmacother. 2009, 63, 120-128. [CrossRef] [PubMed] 
15. Huang, T.; Xiong, Y.; Chen, N.; Wang, D.; Lai, Y.; Deng, C. Highly selective enrichment of baicalin in rat plasma by boronic acid-functionalized core-shell magnetic microspheres: Validation and application to a pharmacokinetic study. Talanta 2016, 147, 501-509. [CrossRef] [PubMed]

16. Lu, C.M.; Lin, L.C.; Tsai, T.H. Determination and pharmacokinetic study of gentiopicroside, geniposide, baicalin, and swertiamarin in Chinese herbal formulae after oral administration in rats by LC-MS/MS. Molecules 2014, 19, 21560-21578. [CrossRef] [PubMed]

17. Chen, H.; Li, Z.; Li, Y.J.; Wu, X.W.; Wang, S.R.; Chen, K.; Zheng, X.X.; Du, Q.; Tang, D.Q. Simultaneous determination of baicalin, oroxylin A-7-O-glucuronide and wogonoside in rat plasma by UPLC-DAD and its application in pharmacokinetics of pure baicalin, Radix Scutellariae and Yinhuang granule. Biomed. Chromatogr. 2015, 29, 1819-1825. [CrossRef] [PubMed]

18. Cui, X.B.; Qian, X.C.; Huang, P.; Zhang, Y.X.; Li, J.S.; Yang, G.M.; Cai, B.C. Simultaneous determination of ten flavonoids of crude and wine-processed Radix Scutellariae aqueous extracts in rat plasma by UPLC-ESI-MS/MS and its application to a comparative pharmacokinetic study. Biomed. Chromatogr. 2015, 29, 1112-1123. [CrossRef] [PubMed]

19. Shan, W.; Cheng, J.; Qu, B.; Sai, J.; Kong, H.; Qu, H.; Zhao, Y.; Wang, Q. Development of a Fluorescence-Linked Immunosorbent Assay for Baicalin. J. Fluoresc. 2015, 25, 1371-1376. [CrossRef] [PubMed]

20. Hong, Y.; He, W.; Li, D.; He, L.; Zhang, W. Preparation and in vitro Anti-tumor Effect of Baicalin Liposome. China J. Exp. Tradit. Med. Formula 2012, 18, 29-31.

21. Chen, Y.J.; Jia, Y.; Jin, R.; Xu, J.Y.; Xing, X.; Yuan, J.L.; Liu, S.Z. Preparation of Baicalin Flexible nano Liposomes. China J. Exp. Tradit. Med. Formula 2011, 17, 1-4.

22. Li, T.; Zhang, L.; Tong, L.; Liao, Q. High-throughput salting-out-assisted homogeneous liquid-liquid extraction with acetonitrile for determination of baicalin in rat plasma with high-performance liquid chromatography. Biomed. Chromatogr. 2014, 28, 648-653. [CrossRef] [PubMed]

23. Gao, R.; Zheng, Q.; Gong, T.; Fu, Y.; Deng, L.; Zhang, Z.R. Gradient high-performance liquid chromatography for the simultaneous determination of chlorogenic acid and baicalin in plasma and its application in the study of pharmacokinetics in rats. J. Pharm. Biomed. Anal. 2007, 43, 335-340. [CrossRef] [PubMed]

24. Qiu, F.; He, Z.G.; Li, H.Z. HPLC analyses and pharmacokinetic studies of baicalin and oxymat-rine in rabbits. Pharmazie 2003, 58, 616-619.

25. Xing, J.; Chen, X.; Zhong, D. Stability of baicalin in biological fluids in vitro. J. Pharm. Biomed. Anal. 2005, 39, 593-600. [CrossRef] [PubMed]

26. Feng, Z.Q.; Han, J.; Xie, Z.Y.; Liao, Q.F.; Zhang, L. Determination of plasma protein binding rate of multicomponent in S cutellaria baicalensis Georgi. Chin. Pharmacol. Bull. 2012, 28, 286-289.

27. Kim, Y.H.; Jeong, D.W.; Paek, I.B.; Ji, H.Y.; Kim, Y.C.; Sohn, D.H.; Lee, H.S. Liquid chrom-atography with tandem mass spectrometry for the simultaneous determinationof baicalein, b-aicalin, oroxylin A and wogonin in rat plasma. J. Chromatogr. B Anal. Technol. Biomed. Life Sci. 2006, 844, 261-267. [CrossRef] [PubMed]

28. Tong, L.; Wan, M.; Zhang, L.; Zhu, Y.; Sun, H.; Bi, K. Simultaneous determination of baicalin, w-ogonoside, baicalein, wogonin, oroxylin $\mathrm{A}$ and chrysin of Radixscutellariae extract in rat pla-sma by liquid chromatography tandem mass spectrometry. J. Pharm. Biomed. Anal. 2012, 70, 6-12. [CrossRef] [PubMed]

29. Xiong, X.; Zhang, L.; Cheng, L.; Mao, W. High-throughput salting-out assisted liquid-liquid extraction with acetonitrile for the determination of anandamide in plasma of hemodialysis patients with liquid chromatography tandem mass spectrometry. Biomed. Chromatogr. 2015, 29, 1317-1324. [CrossRef] [PubMed]

30. Wei, Y.; Zhao, L. Passive lung targeted drug delivery systems via intravenous administration. Pharm. Dev. Technol. 2014, 19, 129-136. [CrossRef] [PubMed]

31. Waser, P.G.; Muller, U.; Kreuter, J.; Berger, S.; Munz, K.; Kaiser, E.; Pfluger, B. Localization of colloidal particles (liposomes, hexylcyanoacrylate nanoparticles and albumin nanoparticles) by histology and autoradigraphy in mice. Int. J. Pharm. 1987, 39, 213-227. [CrossRef]

Sample Availability: Samples of the baicalin loaded liposomes are available from the authors.

(C) 2016 by the authors; licensee MDPI, Basel, Switzerland. This article is an open access article distributed under the terms and conditions of the Creative Commons Attribution (CC-BY) license (http:/ / creativecommons.org/licenses/by/4.0/). 